\title{
Agreement between Creatinine and Cystatin C-Based Equations in the Estimation of Glomerular Filtration Rate among Malaysian Patients with Renal Impairment
}

\author{
Nor Asyikin Mohd Tahir1, Abdul Halim Abdul Gafor², Farida Hanim Islahudin', Shamin Mohd Saffian', \\ Hamizah Abdul Manan ${ }^{3}$, Hanita Othman ${ }^{3}$, Mohd Makmor-Bakry, ${ }^{1, *}$ \\ ${ }^{1}$ Faculty of Pharmacy, Universiti Kebangsaan Malaysia, Kuala Lumpur, MALAYSIA. \\ ${ }^{2}$ Nephrology Unit, Department of Medicine, Universiti Kebangsaan Malaysia Medical Center, Cheras, MALAYSIA. \\ ${ }^{3}$ Department of Pathology, Universiti Kebangsaan Malaysia Medical Center, Cheras, MALAYSIA.
}

\begin{abstract}
Background: Cystatin C-based equations have been proposed as an alternative for creatinine-based equations in the estimation of Glomerular Filtration Rate (eGFR). Limited studies were available with regards to the Asian population to evaluate the agreement of eGFR measured based on both biomarkers. This study aimed to evaluate the agreement between various cystatin C- and creatinine-based eGFR equations. Methods: Patients were recruited from the Nephrology Clinic Universiti Kebangsaan Malaysia Medical Centre. Serum cystatin $C$ and creatinine levels were analysed by particle-enhanced immunoturbidimetry assay and kinetic alkaline picrate method, respectively. Various cystatin C-based (Hoek, Larsson, Grubb, Flodin, cystatin C-based Chronic Kidney Disease Epidemiology (CKD-EPI)) and creatinine-based eGFR equations (Cockcroft-Gault, Modification of Diet in Renal Disease, creatinine-based CKD-EPI) were compared by using the Pearson's correlation and Bland-Altman plot. Results: A total of 118 patients included in this study have a mean age of $61 \pm 15$ years and $57.6 \%$ were female. The mean serum cystatin $C$ and creatinine levels were $2.00 \pm 1.06 \mathrm{mg} / \mathrm{L}$ and $2.21 \pm 1.63$ $\mathrm{mg} / \mathrm{dL}$, respectively. The correlation between serum cystatin $\mathrm{C}$ and creatinine level was significant $(r=0.78, P<0.01)$. All cystatin C-based eGFR correlated significantly with the creatinine-based eGFR equations. The strongest correlation was between creatininebased and cystatin C-based CKD-EPI equation $(r=0.93, P<0.01)$. The Bland-Altman plot shows that cystatin C-based CKD-EPI equation had the least mean difference when compared with creatinine-based CKD-EPI equation. Conclusion: Significant correlation and good agreement were demonstrated between various cystatin C-based and creatininebased eGFR equations. The cystatin $\mathrm{C}$-based equations are appropriate alternative for GFR measurement among Malaysian patients with renal impairment.
\end{abstract}

Key words: Cystatin C, Creatinine, Estimated Glomerular Filtration Rate, Renal Function, Renal Elimination, Chronic Kidney Disease.

\section{INTRODUCTION}

Dosage of renally excreted drugs are commonly estimated based on glomerular filtration rate (eGFR). Creatinine clearance (CLcr) is often used for GFR estimation. A newer biomarker namely cystatin $C$ has been suggested as an alternative biomarker to creatinine in renal function measurement. It is freely filtered by the glomerulus, reabsorbed and metabolized but not secreted by the proximal tubular cells. ${ }^{1}$ It has a constant production rate by all nucleated cell types. ${ }^{2}$ Serum cystatin C level is reported to be independent from other factors such as age, sex, diet, muscle mass and selected diseases. ${ }^{3-6}$ Due to its short
Submission Date: 25-05-2018; Revision Date: 14-08-2018; Accepted Date: 23-10-2018

DOI: 10.5530/ijper.52.4s.106 Correspondence:

Prof. Mohd Makmor Bakry, Faculty of Pharmacy, Universiti Kebangsaan Malaysia, Jalan Raja Muda Abdul Aziz, 50300, Kuala Lumpur, MALAYSIA. Phone no: +603-9289 7244 E-mail: mohdclinpharm@ ukm.edu.my

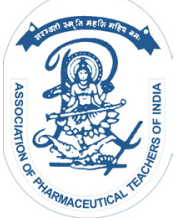

www.ijper.org 
half-life (approximately $2 \mathrm{~h}){ }^{7}$ it reaches steady-state faster than creatinine (half-life $6 \mathrm{~h}$ ). ${ }^{8}$ The fluctuation in serum cystatin $\mathrm{C}$ level is expected to be a more accurate reflection of the current kidney function, thus, avoiding the possibility of overestimation in glomerular filtration rate (GFR) values. This simple, accurate and rapid endogenous substance fulfil the criteria as an ideal biomarker for renal function measurement. A metaanalysis conducted by Dharnidharka et al. found cystatin $\mathrm{C}$ to be superior than creatinine as an endogenous biomarker in estimation of GFR. ${ }^{?}$

In clinical practice, the GFR is routinely estimated based on the clearance of creatinine. Examples of creatininebased equations widely used in clinical practice are Cockcroft-Gault (CG) ${ }^{10}$ Modification of Diet in Renal Disease (MDRD) $)^{11}$ and creatinine-based Chronic Kidney Disease Epidemiology Collaboration (CKD-EPI) Equation. ${ }^{12}$ The usage of creatinine-based equations to estimate renal function often results in an overestimation of the GFR especially in elderly patients due to reduced muscle mass. ${ }^{13}$ This condition could results in higher risk of drug dosing error especially amongst individuals with reduced renal function. ${ }^{14}$ Several other factors such as age, gender, ethnicity, body mass and dietary intake have also been found to influence the level of serum creatinine. ${ }^{3,10}$ It is also lacks in sensitivity in detecting small decrease in GFR and this is known as 'creatinine-blind range. ${ }^{15}$ Therefore, numerous studies recommended cystatin $\mathrm{C}$, as a superior alternative biomarker than creatinine for the estimation of GFR. Several equations have been developed by using serum cystatin C level to estimate GFR, either alone or in combination with serum creatinine. Most of the cystatin C-based equations have lesser covariates because it does not involve parameters such as age, sex, weight and height which is often found in creatinine-based eGFR equations. A cystatin C-based formula developed through a study conducted by Hoek et al. showed a greater accuracy and precision when compared to the CG equation. ${ }^{16}$ Over the years, several other cystatin C-based eGFR equations were developed, such as Larsson, ${ }^{17}$ Grubb $^{18}$ and Flodin ${ }^{19}$ equations. These equations were useful for early detection of renal dysfunction and is a better risk predictor amongst patients with diabetic mellitus when compared to the creatinine-based eGFR equations. ${ }^{20}$ Rapid detection of reduced renal function will allow earlier intervention and hence, prevent further deterioration of kidney problem.

Cystatin C-based eGFR showed a better accuracy in predicting prognosis when compared to creatinine-based eGFR, thus utilisation of cystatin $C$ was suggested. ${ }^{21}$ Both creatinine- and cystatin C-based equations were mostly developed based on the information from the Western population. The creatinine-based equations have been used and established in clinical settings for significant amount of time compared to cystatin C-based equations. Some modification towards creatinine-based equations have been done in some studies to include ethnicity coefficient for the non-western, non-African Americans or in other words, the Asian population. ${ }^{21-22}$ The utilisation of cystatin C-based equations in Asian population has not been extensively explored. As such, validation of the cystatin $\mathrm{C}$-based equations for renal function measurement in Asian population is required.

Another factor associated with the limited use of cystatin $\mathrm{C}$ include the lack of knowledge on the presence of other non-GFR determinants. ${ }^{21}$ Ongoing search to investigate factors affecting cystatin $\mathrm{C}$ production or secretion should be conducted for better use of cystatin C-based equations in terms of GFR estimation, clinical interpretation and prognosis. ${ }^{21}$ The relationship between non-GFR determinants of cystatin $\mathrm{C}$ and its serum concentration could be evaluated by using probable error of a coefficient correlation, developed by Fisher (1921). ${ }^{24}$ The presence of numerous creatinine- and cystatin C-based equations indicated the need for further investigations on the most comparable pairs of equations. Therefore, this study aimed to investigate the agreement of eGFR measured by using cystatin C- and creatininebased eGFR equations among multi-racial Malaysian patients with chronic kidney disease.

\section{MATERIALS AND METHODS}

\section{Patients}

Outpatients attending the Nephrology Clinic Universiti Kebangsaan Malaysia Medical Center (UKMMC), aged more than 18 years old were invited to participate in this observational and cross-sectional study. Patients were recruited from July 2017 until October 2017. These recruited patients were referred to the outpatient nephrology clinic either with general chronic kidney disease problem or renal transplant follow-up. Patients who were currently pregnant, on haemodialysis, diagnosed with Systemic Lupus Erythematosus (SLE) and critically ill were excluded from this study. The study was reviewed and approved by the Research Ethics Committee, Universiti Kebangsaan Malaysia (UKM PPI/111/8/JEP-2017-133) Written informed consent was obtained from all research participants included in the study.

\section{Assay methods}

Fasting blood samples were obtained to determine serum creatinine and cystatin C level. Serum creatinine 
levels were measured by using the standardized-isotope dilution mass spectrometry (IDMS) traceable-kinetic alkaline picrate method on an Architect C System instruments (Abbott Laboratories, Illinois, USA). ${ }^{25}$ The assays were performed in the Department of Diagnostics Laboratory Services, Universiti Kebangsaan Malaysia Medical Centre (UKMMC). The coefficient variation of this method was less than $6 \%$ for between day and within run imprecision. Serum creatinine levels reported as micromol per liter were converted to milligrams per deciliter. Conversion were made since creatinine-based equations used in this study is based on readings of serum creatinine level reported in milligram per deciliter. Serum cystatin C levels were assessed by particleenhanced turbidimetric immunoassay (PETIA) on an ADVIA 1650/1800 Instrument (Siemens Healthcare Diagnostics Inc., Tarrytown, NY, USA) and reported as milligrams per liter. ${ }^{26}$ This method has a coefficient of variation of less than $5 \%$ in the range of 0.1 to $8.3 \mathrm{mg} / \mathrm{L}$. The assays were performed in the Pathology and Clinical Laboratory, Petaling Jaya, Selangor, Malaysia.

\section{Estimation of GFR based on serum creatinine and serum cystatin $\mathrm{C}$ levels}

Creatinine-based eGFR was calculated by using the Cockcroft-Gault (CG), Modification of Diet in Renal Disease (MDRD) and creatinine-based Chronic Kidney Disease Epidemiology Collaboration (Cr-CKD-EPI) equations. Cystatin C-based eGFR was calculated based on the Hoek, Larsson, Grubb, Flodin and cystatin C-based Chronic Kidney Disease Epidemiology Collaboration (CysC-CKD-EPI) equations. Table 1 shows all relevant equations for eGFR. CG and Larsson formula were expressed as $\mathrm{ml} / \mathrm{min} / 1.73 \mathrm{~m}^{2}$ after corrected to body surface area (BSA), based on the Dubois-Dubois formula. ${ }^{27}$

\begin{tabular}{|c|c|}
\hline References & Equations \\
\hline Cockcroft-Gault (CG) $)^{10 *}$ & $\operatorname{eGfR}(\mathrm{ml} / \mathrm{min})=\frac{(140-\text { age }) \times \mathrm{BW}}{72 \times \mathrm{SCr} .}$ \\
\hline Modification of Diet in Renal Disease (MDRD) ${ }^{11 \dagger}$ & $\begin{array}{c}\text { eGFR }\left(\mathrm{ml} / \mathrm{min} / 1.73 \mathrm{~m}^{2}\right)=175 \times \mathrm{SCr}^{-1.154} \times \mathrm{Age}^{-0.203} \times \mathrm{G} \times \mathrm{E} \\
\mathrm{G}=0.742 \text { if female. } 1 \text { if male } \\
\mathrm{E}=1.21 \text { if African American, } 1 \text { if non-African American }\end{array}$ \\
\hline $\begin{array}{l}\text { Creatinine-based Chronic Kidney Disease - Epidemiology } \\
\qquad(\text { CKD-EPI })^{12 \dagger}\end{array}$ & 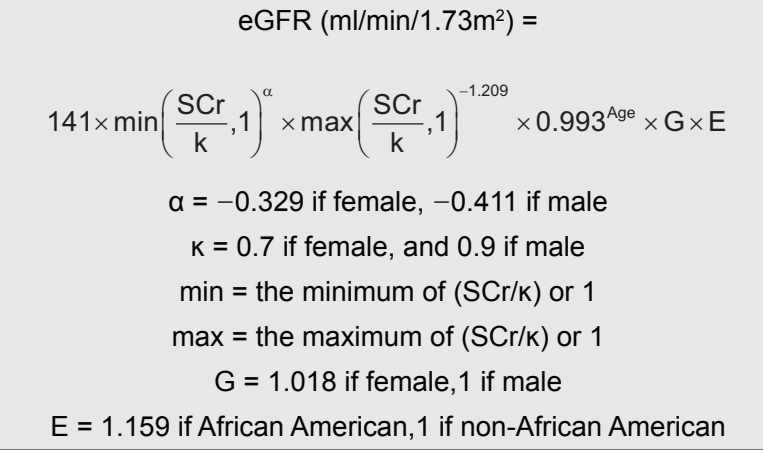 \\
\hline Hoek Equation ${ }^{16 \dagger}$ & eGfR $\left(\mathrm{ml} / \mathrm{min} / 1.73 \mathrm{~m}^{2}\right)=\frac{80.35}{\text { SCysC }}=4.32$ \\
\hline Larsson Equation ${ }^{17 *}$ & eGFR $(\mathrm{ml} / \mathrm{min})=77.24 \times \mathrm{SCysC}^{-1.2623}$ \\
\hline Grubb Equation ${ }^{18 \dagger}$ & eGFR $\left(\mathrm{ml} / \mathrm{min} / 1.73 \mathrm{~m}^{2}\right)=84.69 \times \mathrm{SCysC}^{-1.680}$ \\
\hline Flodin Equation $^{19 \dagger}$ & eGFR $\left(\mathrm{ml} / \mathrm{min} / 1.73 \mathrm{~m}^{2}\right)=79.901 \times \mathrm{SCysC}^{-1.4389}$ \\
\hline Cystatin C-based CKD-EPI ${ }^{45 \dagger}$ & $\begin{array}{c}\text { eGFR }\left(\mathrm{ml} / \mathrm{min} / 1.73 \mathrm{~m}^{2}\right)= \\
133 \times \min \left(\frac{\text { SCysC }}{0.8}, 1\right)^{-0.499} \times \max \left(\frac{\mathrm{SCysC}}{0.8}, 1\right)^{-1.328} \times 0.996^{\mathrm{Age}} \times \mathrm{G} \\
\min =\text { the minimum of }(\mathrm{SCysC} / 0.8) \text { or } 1 \\
\max =\text { the maximum of }(\mathrm{SCys} / 0.8) \text { or } 1 \\
\mathrm{G}=0.932 \text { if female }, 1 \text { if male }\end{array}$ \\
\hline
\end{tabular}

BW, body weight in $\mathrm{kg}$; $\mathrm{SCr}$, serum creatinine in $\mathrm{mg} / \mathrm{dL} ; \mathrm{G}$, gender factor; $\mathrm{E}$, ethnicity factor; $\mathrm{SCys}$, serum cystatin $\mathrm{C}$ in $\mathrm{mg} / \mathrm{L}$.

*Corrected to body surface area $\left(B S A, \mathrm{~m}^{2}\right)=0.007184 \times$ height $(\mathrm{cm})^{0.725} \times$ weight $(\mathrm{kg})^{0.425}$

${ }^{+}$Already expressed per body surface are (BSA) 


\section{Statistical analysis}

Data were analyzed by using IBM Statistical Package for Social Science (SPSS) Statistics for Windows, Version 21 (IBM Corp, Armonk, NY) and MedCalc for Windows, Version 17.9.7 (MedCalc Software, Ostend, Belgium). Categorical variables were presented as frequency, $\mathrm{n}$ and percentages (\%) while continuous variables were presented as mean \pm standard deviation (SD). The correlation and presence of any significant difference between mean serum cystatin $C$ levels and cystatin $\mathrm{C}$-based eGFR with mean serum creatinine levels and creatinine-based eGFR were investigated using Pearson's Correlation and Wilcoxon Signed-Rank test. The Bland-Altman plot was used to evaluate the agreement between eGFR values obtained by using the creatinine and cystatin C-based equations. Bias was defined as the systematic deviation of cystatin C-based eGFR from the creatinine-based eGFR. This systematic deviation was expressed as mean bias $\pm 95 \%$ confidence interval (CI) of the difference plots. The difference of eGFR values derived from the two equations on the $\mathrm{y}$-axis were plotted against the means of the two measurements on the $\mathrm{x}$-axis. The line of mean difference as well as 95\% upper and lower limits of agreement (mean bias $\pm 1.96 \times \mathrm{SD}$ ) were plotted. The relationship between the differences and means of two measurements was assessed by using simple linear regression of the plots, of which slopes exhibiting $\pm 95 \%$ CI were recorded. $P$-value $<0.05$ were considered statistically significant in this study.

\section{RESULTS}

\section{Baseline characteristics}

A total of 118 patients were included in this study. The mean age was $61 \pm 15$ years with $57.6 \%$ being female and majority were Malays (55.9\%). The mean serum creatinine and cystatin C level were $2.21 \pm 1.63 \mathrm{mg} / \mathrm{dL}$ (0.61-9.08 $\mathrm{mg} / \mathrm{dL})$ and $2.00 \pm 1.06 \mathrm{mg} / \mathrm{L}(0.63-7.80$ $\mathrm{mg} / \mathrm{L})$, respectively. Other baseline characteristics are summarised in Table 2.

\section{Correlation of creatinine- and cystatin C-based eGFR values}

The correlation between serum cystatin $C$ and creatinine level was statistically significant $(\mathrm{r}=0.78, P<0.05)$ (Figure 1A). Meanwhile, a similar trend of inverse relationship was observed between serum creatinine and creatinine-based eGFR as well as serum cystatin C and cystatin C-based eGFR. The Pearson's Correlation analysis also shows a statistically significant relationship
Table 2: Patient demographic information and overall renal function data.

\begin{tabular}{|c|c|}
\hline & n (\%) \\
\hline $\begin{array}{l}\text { Gender } \\
\text { Male } \\
\text { Female }\end{array}$ & $\begin{array}{l}50(42.4) \\
68(57.6)\end{array}$ \\
\hline $\begin{array}{l}\text { Race } \\
\text { Malay } \\
\text { Chinese } \\
\text { Indian } \\
\text { Other }\end{array}$ & $\begin{array}{c}66(55.9) \\
44(37.4) \\
7(5.9) \\
1(0.8)\end{array}$ \\
\hline & Mean $\pm S D$ \\
\hline Age (years) & $61 \pm 15$ \\
\hline Weight $(\mathrm{kg})$ & $70 \pm 15$ \\
\hline Height $(\mathrm{m})$ & $1.61 \pm 0.08$ \\
\hline $\operatorname{BMI}\left(\mathrm{kg} / \mathrm{m}^{2}\right)$ & $27.21 \pm 7.79$ \\
\hline Serum Creatinine $(\mathrm{Cr})(\mathrm{mg} / \mathrm{dL})$ & $2.21 \pm 1.63$ \\
\hline Serum Cystatin C (CysC) (mg/L) & $2.00 \pm 1.06$ \\
\hline eGFR_Cr-CG $\left(\mathrm{ml} / \mathrm{min} / 1.73 \mathrm{~m}^{2}\right)^{*}$ & $48.44 \pm 34.66$ \\
\hline eGFR_Cr-MDRD $\left(\mathrm{ml} / \mathrm{min} / 1.73 \mathrm{~m}^{2}\right)^{\dagger}$ & $41.98 \pm 28.36$ \\
\hline eGFR_Cr-CKD-EPI $\left(\mathrm{ml} / \mathrm{min} / 1.73 \mathrm{~m}^{2}\right)^{\dagger}$ & $44.34 \pm 31.09$ \\
\hline eGFR_CysC-Hoek $\left(\mathrm{ml} / \mathrm{min} / 1.73 \mathrm{~m}^{2}\right)^{\dagger}$ & $47.29 \pm 26.44$ \\
\hline eGFR_CysC-Larsson $\left(\mathrm{ml} / \mathrm{min} / 1.73 \mathrm{~m}^{2}\right)^{*}$ & $46.75 \pm 30.91$ \\
\hline eGFR_CysC-Grubb $\left(\mathrm{ml} / \mathrm{min} / 1.73 \mathrm{~m}^{2}\right)^{\dagger}$ & $46.06 \pm 39.89$ \\
\hline eGFR_CysC-Flodin $\left(\mathrm{ml} / \mathrm{min} / 1.73 \mathrm{~m}^{2}\right)^{\dagger}$ & $45.57 \pm 33.75$ \\
\hline eGFR_CysC-CKD-EPI $\left(\mathrm{ml} / \mathrm{min} / 1.73 \mathrm{~m}^{2}\right)^{\dagger}$ & $43.52 \pm 29.81$ \\
\hline
\end{tabular}

Data are presented as number (\%) or mean \pm SD.

$\mathrm{BMI}$, body mass index; eGFR, estimated glomerular filtration rate; CG, CockcroftGault; MDRD, Modification of Diet in Renal Disease; Cr-CKD-EPI, Creatinine-based Chronic Kidney Disease Epidemiology Collaboration; CysC-CKD-EPI, Cystatin C-based Chronic Kidney Disease Epidemiology Collaboration equations.

"Corrected to body surface area $\left(B S A, m^{2}\right)=0.007184$ ×height $(\mathrm{cm})^{0.725 \times w e i g h t ~}$ $(\mathrm{kg})^{0.425}$

${ }^{+}$Already expressed as BSA
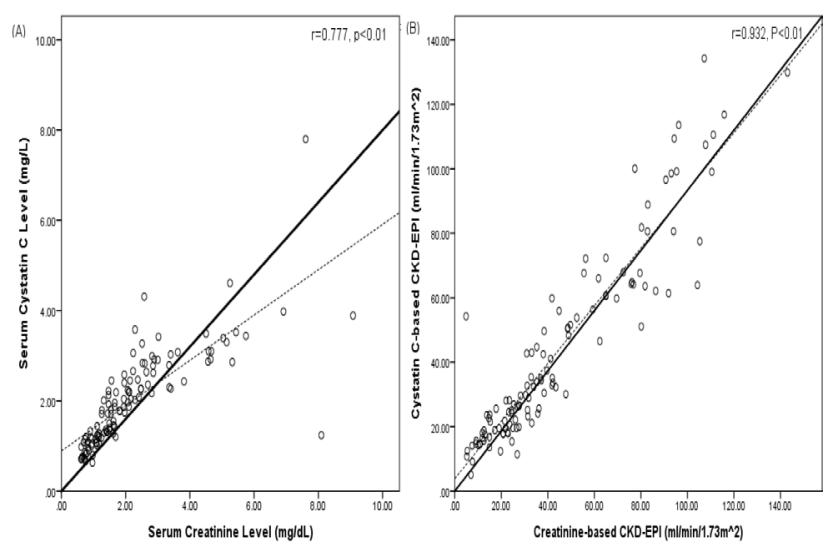

Figure 1: Comparison of serum cystatin C, cystatin C-based eGFR with serum creatinine and creatinine-based eGFR (A) Correlations between serum cystatin $C$ and creatinine level.

(B) Correlations of eGFR values derived from cystatin C-based CKD-EPI and creatinine-based CKD-EPI equation. The solid line is the line of identity. The dotted line is the trend line. eGFR, estimated Glomerular Filtration Rate; CKDEPI, Chronic Kidney Disease Epidemiology Collaboration. 
Table 3: Correlation between creatinine- and cystatin C-based eGFR from various equations ( $n=118$.

\begin{tabular}{|c|c|c|c|c|c|c|c|}
\hline & & \multirow{2}{*}{$\mathrm{SCr}$} & \multicolumn{5}{|c|}{ Cystatin C-based eGFR equations } \\
\hline & & & Hoek & Larsson & Grubb & Flodin & CysC-CKD-EPI \\
\hline \multicolumn{2}{|c|}{ SCysC } & $0.78^{*}$ & $-0.83^{*}$ & $-0.79^{*}$ & $-0.75^{\star}$ & $-0.78^{*}$ & $-0.79^{*}$ \\
\hline \multirow{3}{*}{$\begin{array}{l}\text { Creatinine-based } \\
\text { eGFR equations }\end{array}$} & CG & $-0.66^{*}$ & $0.86^{*}$ & $0.81^{*}$ & $0.85^{*}$ & $0.86^{*}$ & $0.89^{*}$ \\
\hline & MDRD & $-0.72^{*}$ & $0.90^{*}$ & $0.89^{*}$ & $0.89^{*}$ & $0.89^{*}$ & $0.92^{*}$ \\
\hline & Cr-CKD-EPI & $-0.72^{*}$ & $0.92^{*}$ & $0.90^{*}$ & $0.90^{*}$ & $0.91^{*}$ & $0.93^{*}$ \\
\hline
\end{tabular}

Data from Pearson's Correlation test. eGFR, estimated glomerular filtration rate; CG, Cockcroft-Gault; MDRD, Modification of Diet in Renal Disease; Cr-CKD-EPI, creatininebased Chronic Kidney Disease Epidemiology Collaboration; CysC-CKD-EPI, cystatin C-based Chronic Kidney Disease Epidemiology Collaboration equations. *Significant at $p<0.05$

\begin{tabular}{|c|c|c|c|c|}
\hline \multicolumn{2}{|c|}{ Equations } & \multirow{2}{*}{$\begin{array}{c}\text { Mean bias } \\
(95 \% \mathrm{Cl})\left(\mathrm{ml} / \mathrm{min} / 1.73 \mathrm{~m}^{2}\right)\end{array}$} & \multirow{2}{*}{$\begin{array}{l}95 \% \text { limits of agreement } \\
\text { around the mean bias }(\mathrm{ml} / \\
\left.\min / 1.73 \mathrm{~m}^{2}\right)\end{array}$} & \multirow{2}{*}{$\begin{array}{l}\text { Slope of difference plot } \\
\qquad(95 \% \mathrm{Cl})\end{array}$} \\
\hline $\begin{array}{l}\text { Cystatin-C } \\
\text { based }\end{array}$ & Creatinine-based & & & \\
\hline Hoek & $\begin{array}{c}\text { CG } \\
\text { MDRD } \\
\text { Cr-CKD-EPI }\end{array}$ & $\begin{array}{l}-1.2(-4.4,2.1) \\
5.3(3.1,7.5)^{*} \\
2.9(0.7,5.2)^{*}\end{array}$ & $\begin{array}{l} \pm 35.1 \\
\pm 24.0 \\
\pm 24.5\end{array}$ & $\begin{array}{c}-0.29(-0.39,-0.19)^{\dagger} \\
-0.07(-0.16,0.01) \\
-0.17(-0.24,-0.09)^{\dagger}\end{array}$ \\
\hline Larsson & $\begin{array}{c}\text { CG } \\
\text { MDRD } \\
\text { Cr-CKD-EPI }\end{array}$ & $\begin{array}{c}-1.6(-5.4,2.1) \\
4.9(2.23,7.52)^{*} \\
2.5(-0.1,5.1)\end{array}$ & $\begin{array}{l} \pm 40.1 \\
\pm 28.3 \\
\pm 27.6\end{array}$ & $\begin{array}{c}-0.13(-0.24,-0.01)^{\dagger} \\
0.09(0.00,0.18)^{\dagger} \\
-0.01(-0.09,0.08)\end{array}$ \\
\hline Grubb & $\begin{array}{c}\text { CG } \\
\text { MDRD } \\
\text { Cr-CKD-EPI }\end{array}$ & $\begin{array}{l}-2.4(-6.2,1.5) \\
4.1(0.5,7.7)^{*} \\
1.7(-1.6,5.0)\end{array}$ & $\begin{array}{l} \pm 41.5 \\
\pm 38.8 \\
\pm 35.4\end{array}$ & $\begin{array}{l}0.15(-0.05,0.26)^{\dagger} \\
0.36(0.27,0.45)^{\dagger} \\
0.26(0.18,0.34)^{\dagger}\end{array}$ \\
\hline Flodin & $\begin{array}{c}\text { CG } \\
\text { MDRD } \\
\text { Cr-CKD-EPI }\end{array}$ & $\begin{array}{l}-2.9(-6.2,0.5) \\
3.6(0.8,6.4)^{*} \\
1.2(-1.3,3.8)\end{array}$ & $\begin{array}{l} \pm 36.1 \\
\pm 29.8 \\
\pm 27.5\end{array}$ & $\begin{array}{l}-0.03(-0.13,0.07) \\
0.18(0.10,0.27)^{\dagger} \\
0.09(0.01,0.17)^{\dagger}\end{array}$ \\
\hline CysC-CKD-EPI & $\begin{array}{c}\text { CG } \\
\text { MDRD } \\
\text { Cr-CKD-EPI }\end{array}$ & $\begin{array}{c}-4.9(-7.8,-2.0)^{*} \\
1.5(-0.6,3.7) \\
-0.8(-2.9,1.2)\end{array}$ & $\begin{array}{l} \pm 31.1 \\
\pm 29.8 \\
\pm 22.1\end{array}$ & $\begin{array}{c}-0.16(-0.25,-0.07)^{\dagger} \\
0.05(-0.02,0.13) \\
-0.04(-0.11,0.03)\end{array}$ \\
\hline
\end{tabular}

Data from Bland-Altman analysis. eGFR, estimated glomerular filtration rate; CG, Cockcroft-Gault; MDRD, Modification of Diet in Renal Disease; Cr-CKD-EPI, creatininebased Chronic Kidney Disease Epidemiology Collaboration; CysC-CKD-EPI, cystatin C-based Chronic Kidney Disease Epidemiology Collaboration.

*Presence of statistically significant bias

${ }^{\dagger}$ Presence of statistically significant proportional bias

between all creatinine- and cystatin C-based GFR estimates (Table 3). The strongest correlation was observed between cystatin C-based and creatinine-based CKD-EPI equations $(r=0.93, P<0.01)$ (Figure $1 \mathrm{~B})$.

\section{Presence of mean difference between creatinine- and cystatin C-based eGFR values}

Wilcoxon Signed-Rank test demonstrated a presence of significant difference between seven pairs of eGFR values, calculated using cystatin $\mathrm{C}$-based and creatininebased eGFR equations (Grubb and CG, $Z=-2.98, P=0.003$; Flodin and $C G, Z=-2.28, P=0.023$; cystatin $C$-based CKD-EPI and CG, $Z=-3.361, P=0.01$; Hoek and MDRD, $Z=-5.66, \quad P<0.01$; Larsson and MDRD, $Z=-3.88, P<0.01$; Hoek and creatinine-based CKD-EPI, $Z=-3.52, P<0.01$; and Larsson and creatinine-based CKD-EPI, $Z=-2.46, P=0.014)$. Even though eGFR values calculated based on Hoek and creatinine-based CKD-EPI equations produced a significantly strong correlation $(\mathrm{r}=0.918, P<0.01)$, the Wilcoxon's Signed-
Rank test shows the presence of a significant difference between the mean of eGFR values derived from these two equations $(P<0.01)$.

\section{Bias and imprecision between creatinine- and cystatin C-based eGFR values}

The performances of the eight equations are presented in Table 4 and Figure 2 (A-O). The presence of bias between eGFR values obtained by using the following pairs of equations were not statistically significant. The paired cystatin C- and creatinine-based equations were Hoek and CG $(P=0.490)$, Larsson and CG $(P=0.390)$, Larsson and Cr-CKD-EPI $(P=0.059)$, Grubb and CG $(P=0.226)$, Grubb and Cr-CKD-EPI $(P=0.301)$, Flodin and CG $(P=0.094)$, Flodin and $C r-$ CKD-EPI $(P=0.343)$, CysC-CKD-EPI and MDRD $(P=0.158)$ and CysC-CKD-EPI and Cr-CKD-EPI $(P=0.434)$ equations. In contrast, the rest of the paired measurements used in this study were found to have the presence of a statistically significant bias. 
Figure 2: (A-O) Bland-Altman plots between each cystatin C-based and creatinine-based eGFR equations. The $x$-axis is the mean of creatinine- and cystatin C- based eGFR values. The y-axis is the difference between the two eGFR values. The solid line indicates the mean difference. The upper and lower horizontal dotted lines indicate the line for limits of agreement (mean \pm 1.96SD). The dashed line indicates the regression line of differences.

\begin{tabular}{|c|c|c|c|c|}
\hline & & & reatinine-based Equatic & \\
\hline & & CG Equation & MDRD Equation & $\begin{array}{c}\text { Creatinine-based CKD-EPI } \\
\text { Equation }\end{array}$ \\
\hline 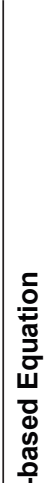 & 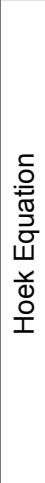 & 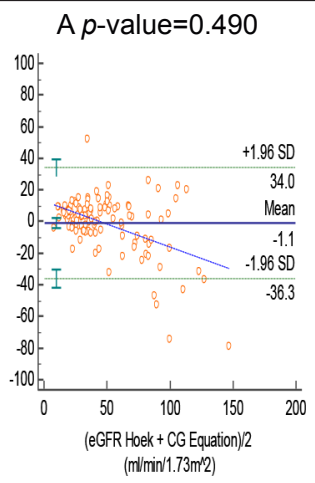 & 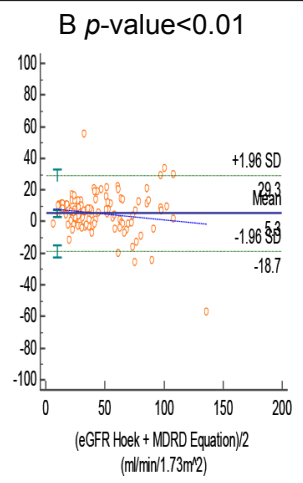 & 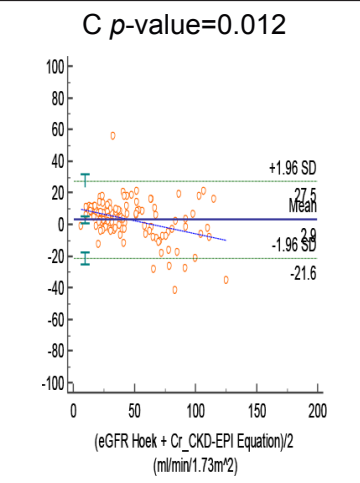 \\
\hline 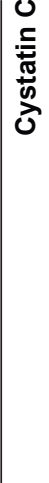 & 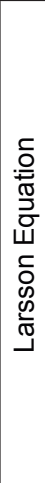 & 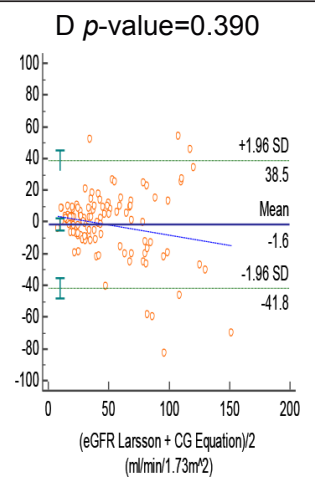 & 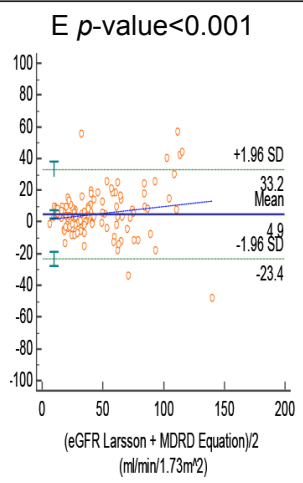 & $\begin{array}{l}\text { F } p \text {-value }=0.059 \\
\end{array}$ \\
\hline & & & reatinine-based Equatic & \\
\hline & & CG Equation & MDRD Equation & $\begin{array}{c}\text { Creatinine-based CKD-EPI } \\
\text { Equation }\end{array}$ \\
\hline 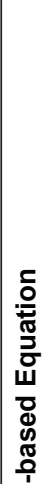 & 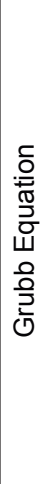 & 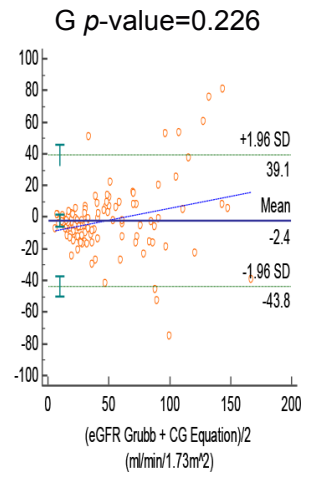 & $\begin{array}{l}\mathrm{H} p \text {-value }=0.027 \\
\end{array}$ & 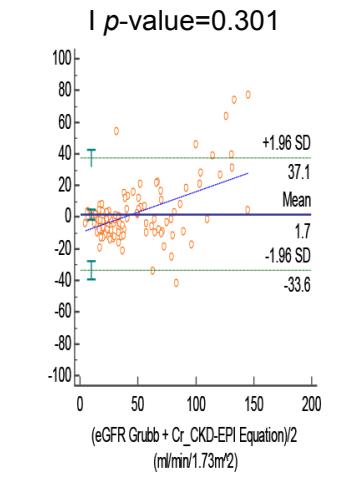 \\
\hline 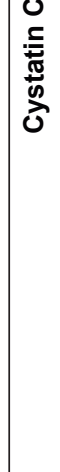 & 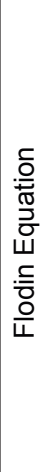 & 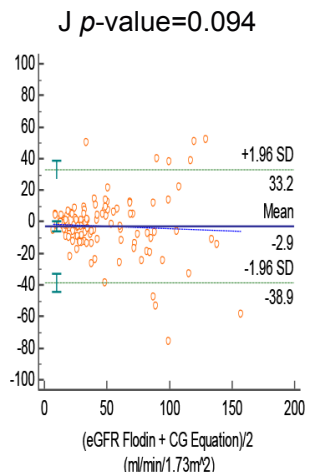 & 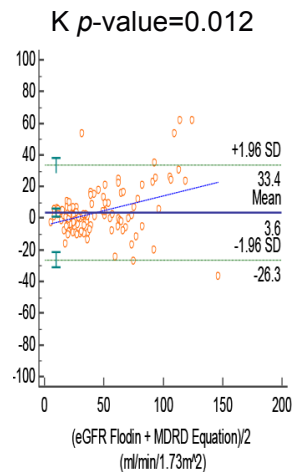 & 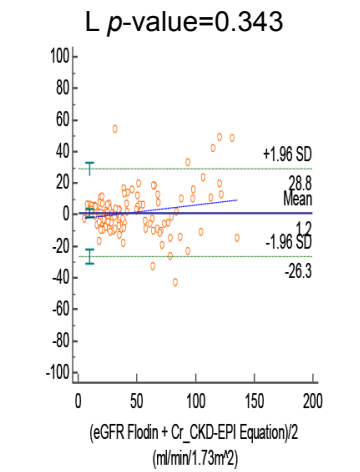 \\
\hline
\end{tabular}




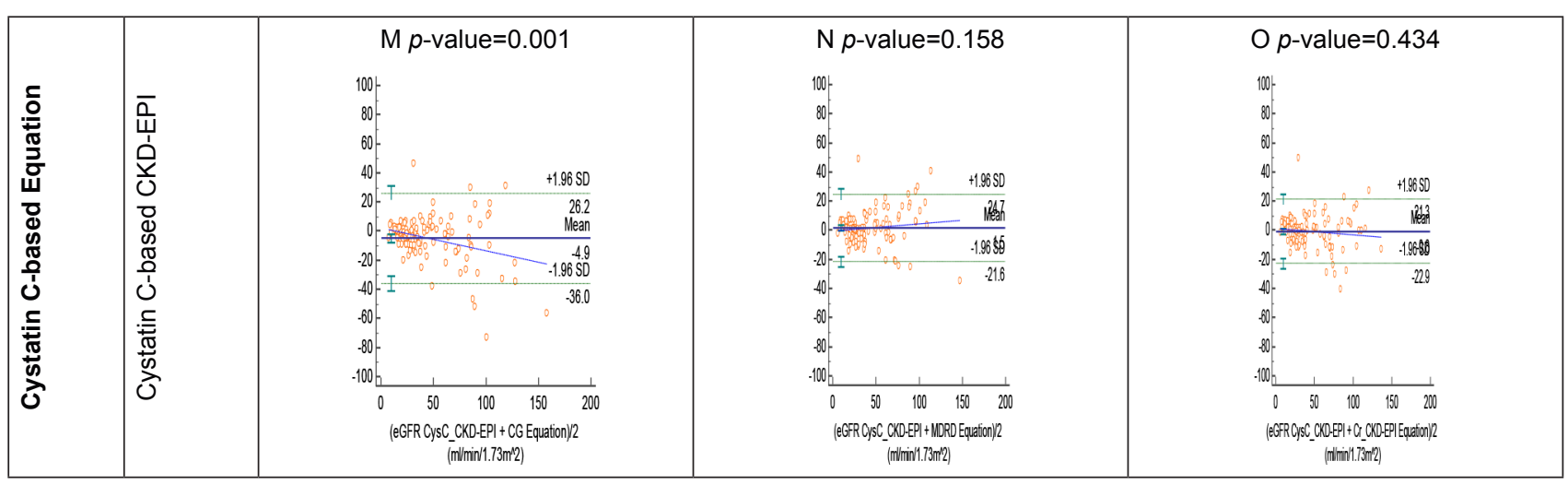

eGFR, estimated glomerular filtration rate; CG, Cockcroft-Gault; MDRD, Modification of Diet in Renal Disease; Cr_CKD-EPI, Creatinine-based Chronic Kidney Disease Epidemiology Collaboration; CysC_CKD-EPI, Cystatin C-based Chronic Kidney Disease Epidemiology Collaboration equations; SD, standard deviation.

\section{DISCUSSION}

Cystatin C is an ideal biofiltration marker due to its low molecular weight and constant production rate by all nucleated cells. ${ }^{28}$ In a study involving handling of human cystatin $\mathrm{C}$ in rats, the clearance of cystatin $\mathrm{C}$ from the kidney is equivalent to $94 \%$ clearance of ${ }^{51-} \mathrm{CR}$ EDTA. ${ }^{29}$ Meanwhile, Northern blot and Immunohistochemical studies conducted shows that $99 \%$ of the filtered cystatin $\mathrm{C}$ undergoes degradation in proximal tubule. ${ }^{30}$ This indicates that cystatin $\mathrm{C}$ is freely filtered in the glomerulus and were then reabsorbed and catabolized at the tubular cells. ${ }^{28,31}$ Besides, unlike creatinine, cystatin $C$ is not influenced by age, height, sex or muscle mass. ${ }^{32}$ These special features of cystatin $\mathrm{C}$ suggested that utilizing it as an endogenous biomarker will results in a more accurate renal function measurement.

Due to the significance of cystatin $C$ as a potentially ideal biomarker, we evaluated the association between serum cystatin $\mathrm{C}$ - and serum creatinine-based equations to estimate GFR. In this study, we successfully demonstrated a strong correlation between all cystatin C- and creatinine-based eGFR equations among Malaysian patients with chronic kidney disease. Despite the good correlation shown, the mean eGFR values derived from some cystatin C- and creatinine-based eGFR shows a statistically significant difference. Therefore, further analysis of Bland-Altman plot was conducted to investigate which cystatin C-based eGFR demonstrated the least mean difference from creatinine-based eGFR equations.

All eGFR values obtained by using cystatin C-based equations shows a statistically significant positive correlation with creatinine-based equations, indicating the presence of general comparability between them. This result is consistent with findings from previously published study conducted by Lee et al involving 615 CKD patients. ${ }^{33}$ Six cystatin C-based eGFR equations
(Larsson, Hoek, Le Bricon, Filler, Orebro cystatin C (DAKO) and Orebro cystatin C (Gentian)) and Korean population based MDRD eGFR equation were compared..$^{33}$ In this current study, the strongest correlation found was between the creatinine-based and cystatin C-based CKD-EPI equation. However, high correlation coefficients do not automatically suggest these equations as the most accurate version of cystatin $\mathrm{C}$ - and creatinine-based formula for GFR estimation. Instead, correlation coefficient values should only be interpreted as presence of an association or relationship between the two variables. ${ }^{34}$ Two sets of different methods of measurements for the same parameter will be expected to have a good correlation. ${ }^{34}$ From this viewpoint, significant correlation will be achieved even if the two methods of measurements do not well agree. ${ }^{34}$ Hence, the application of correlation coefficient alone is not always appropriate with respect to this matter.

Even though a strong correlation was previously demonstrated, the differences in the mean eGFR values derived from some creatinine and cystatin C-based eGFR equations were statistically significant. For example, the correlation of eGFR values obtained by using Hoek and CKD-EPI equations. The regression analysis of Hoek and CKD-EPI equation indicate presence of good agreement with a statistically significant correlation coefficient, $\mathrm{r}=0.92, \mathrm{p}<0.01$. However, analysis based on Wilcoxon Signed rank test shows the presence of a statistically significant mean difference in the values of eGFR derived from these equations. Thus, the unit of deviation between the two methods of measurement needs to be quantitatively measured. Analysis based on Bland-Altman plot were conducted to further investigate the agreement between the cystatin C- and creatininebased eGFR equations. ${ }^{34}$

Comparing a new clinical measurement method with the established one is essential to determine whether the values calculated are in congruence with each other for 
such replacement to take place. ${ }^{34}$ In the Bland-Altman analysis, presence of non-significant bias was identified in nine pairs of cystatin C-and creatinine-based eGFR. The smallest mean difference found based on these pairs of eGFR equations is between cystatin C-based and creatinine-based CKD-EPI formula. Good agreement shown suggests that the cystatin C-based equations is comparable to creatinine-based equations. Further analysis on the forms of systematic difference existed was conducted by using simple linear regression slopes of the difference plots. Most pairs of equation have a positive bias at a lower eGFR values and negative bias at a higher eGFR values. As such, the creatininebased eGFR values were higher amongst patient with high renal function and vice versa compared to cystatin C-based eGFR values. Previously published literature incorporating analyses of these selected creatinine and cystatin C-based eGFR equations were limited. Performance of cystatin C-based equations (Larsson, Hoek, Le Bricon, Filler and Orebro) has been compared with MDRD in Korean populations by using Bland-Altman plot whereby, the smallest mean difference from baseline was found in Filler equation $\left(0.39 \mathrm{ml} / \mathrm{min} / 1.73 \mathrm{~m}^{2}\right) .^{33}$ Meanwhile, Xirouchakis et al. compared ${ }^{51} \mathrm{Cr}$-EDTA GFR with MDRD, Larsson and Hoek equations. ${ }^{35}$ Since comparison was made based on the reference GFR, the conclusion made based on the study is that Hoek and MDRD is the most accurate and precise equation, respectively. ${ }^{35}$ In another recent study conducted among Malaysian elderly patients, cystatin C-based CKD-EPI were found to have a greater degree of biasness, lower imprecision and lesser accuracy compared to creatininebased CKD-EPI and MDRD equation. ${ }^{36}$ Different standardization of the cystatin $C$ value used in the original CKD-EPI equation, small sample size and imbalanced number of patients in each CKD stage could possibly results in this unexpected finding. On the contrary, a study conducted by Marwyne et al. (2011) among obese patients found cystatin C-based eGFR to be superior than creatinine-based eGFR in terms of accuracy, sensitivity and specificity. ${ }^{37}$ The association of serum creatinine with weight and muscle mass could be one of the contributing factors that led to poor performance of creatinine-based eGFR when compared with cystatin C-based eGFR.

The present study provides evidence that the cystatin C-based equations are comparable to the creatininebased equations for estimating GFR. Prediction equations based on serum cystatin $\mathrm{C}$ level only, without any or even with less covariates is able to give a good estimate of GFR. ${ }^{16}$ Some studies also revealed a higher accuracy and precision of eGFR values obtained by using cystatin
C-based equations than the CG and simplified MDRD equation. ${ }^{16,18}$ Cystatin C-based equations also demonstrated a better performance compared to creatininebased equations in estimating GFR for certain group of people such as patients with liver cirrhosis. Since this group of patients have poor prognosis of renal impairment, employing cystatin C-based approach such as Hoek and Larsson formula could result in significant improvement of the GFR estimation. ${ }^{38}$ Besides, eGFR equations based on cystatin $\mathrm{C}$ may also be appropriate for drug dosing. This is supported by several studies conducted in the recent years to evaluate the usefulness of cystatin $\mathrm{C}$ as a biomarker for dose prediction of renally excreted drugs such as vancomycin, gentamicin and amikacin. It was found that cystatin $\mathrm{C}$ demonstrated a better correlation with clearance or trough level of selected drugs being evaluated when compared with creatinine. ${ }^{39-41}$

An important limitation of this study was the absence of a gold standard reference GFR (rGFR) for comparison, such as inulin, iohexol or radioactive isotopes (i.e. ${ }^{51} \mathrm{Cr}$ EDTA, ${ }^{99 \mathrm{~m}}$-TC-DTPA, ${ }^{25}$ I-Iothalamate). This limits the ability of this study to determine which equation has the best predictive performance in terms of estimating the measured GFR. Clearance measurement of these exogeneous substances were relatively expensive, invasive and labour intensive. ${ }^{42}$ This is the same case in real clinical practice. Even though utilising the gold standard GFR measurement is very ideal and preferable, applying it in a big study population would be very costly and could results in a lot of complexities. ${ }^{43,44}$

Our future work will involve investigating factors affecting serum cystatin $\mathrm{C}$ level and cystatin C-based eGFR equations. Therefore, identification of the specific cystatin C-based equations which complement creatinine-based equations is required. Based on the positive correlation and good agreement shown between creatinine-based and cystatin C-based CKD-EPI equations, other factors such as genetic influence, drug and clinical factors that might affect cystatin C-based eGFR measurement could be investigated in our population. A better understanding on factors affecting serum cystatin $\mathrm{C}$ levels independent of GFR is highly crucial for better utilisation of cystatin C-based equations in clinical practice. ${ }^{21}$

\section{CONCLUSION}

Cystatin C-based equations are comparable with the creatinine-based equations for eGFR measurement among multi-racial Malaysian patients with CKD. Cystatin C was able to give a good estimate of GFR even with lesser covariates compared to creatinine-based 
equations. There was a good agreement shown between cystatin C- and creatinine- based equations to estimate GFR. eGFR values derived from cystatin C-based CKD-EPI equation shows a strong correlation and the least mean difference from baseline when compared with creatinine-based CKD-EPI equation.

\section{ETHICAL APPROVAL}

All procedures conducted in this study involving human participants were in accordance with the ethical standards of the institutional and/or national research ethics committee and with the 1964 Helsinki declaration and its later amendments or comparable ethical standards. The study was reviewed and approved by the Research Ethics Committee of Universiti Kebangsaan Malaysia (UKM PPI/111/8/JEP-2017-133).

\section{INFORMED CONSENT}

Written informed consent was obtained from all research participants included in the study.

\section{ACKNOWLEDGEMENT}

This study was funded by the Fundamental Research Grant Scheme (FRGS), Ministry of Higher Education, Malaysia (FRGS/1/2016/SKK09/UKM/02/3). The authors would like to thank all medical doctors, nurses and phlebotomist of Universiti Kebangsaan Malaysia Medical Center (UKMMC) for their help in this study.

\section{CONFLICT OF INTEREST}

All authors declare that they did not have any conflict of interest.

\section{ABBREVIATIONS}

GFR: Glomerular Filtration Rate; eGFR: Estimated Glomerular Filtration Rate; BW: Body Weight; BMI: Body Mass Index; Scr: Serum Creatinine; ScysC: Serum Cystatin C; G: Gender; E: Ethnicity; BSA: Body Surface Area; CG: Cockcroft-Gault; MDRD: Modification of Diet in Renal Disease; CKD: Chronic Kidney Disease; CKD-EPI: Chronic Kidney Disease-Epidemiology Collaboration Equation.

\section{REFERENCES}

1. Newman DJ, Thakkar H, Edwards RG, Wilkie M, White T, Grubb AO. Serum cystatin $C$ measured by automated immunoassay: a more sensitive marker of changes in GFR than serum creatinine. Kidney Int. 1995;47(1):312-18.

2. Abrahamson M, Olafsson I, Palsdottir A, Ulvsback M, Lundwall A, Jensson $\mathrm{O}$, Structure and expression of the human cystatin $\mathrm{C}$ gene. Biochem J. 1990;268(2):287-94
3. Baxmann AC, Ahmed MS, Marques NC, Menon VB, Pereira AB, Kirsztajn GM. Influence of muscle mass and physical activity on serum and urinary creatinine and serum cystatin C. Clin J Am Soc Nephrol. 2008;3(2):348-54.

4. Filler G, Bökenkamp A, Hofmann W, Le Bricon T, Martínez-Brú C, Grubb A. Cystatin $C$ as a marker of GFR-history, indications and future research. Clin Biochem. 2005;38(1):1-8.

5. Harmoinen APT, Kouri TT, Wirta OR, Lehtimaki TJ, Rantalaiho V, Turjanmaa VMH. Evaluation of plasma cystatin $\mathrm{C}$ as a marker for glomerular filtration rate in patients with type 2 diabetes. Clin Nephrol. 1999;52:363-70.

6. Woitas RP, Stoffel-Wagner B, Flommersfeld S, Poege U, Schiedermaier P, Klehr HU, . Correlation of serum concentrations of cystatin $\mathrm{C}$ and creatinine to inulin clearance in liver cirrhosis. Clin Chem. 2000;46(5):712-15.

7. Sjöström P, Tidman M, Jones I. The shorter T1/2 of cystatin $C$ explains the earlier change of its serum level compared to serum creatinine. Clin Nephrol. 2004;62(3):241-42.

8. Bjornsson TD. Use of serum creatinine concentrations to determine renal function. Clin Pharmacokinet. 1979;4(3):200-22.

9. Dharnidharka VR, Kwon C, Stevens G. Serum cystatin $C$ is superior to serum creatinine as a marker of kidney function: A meta-analysis. Am J Kidney Dis. 2002;40(2):221-26.

10. Cockcroft DW, Gault MH. Prediction of creatinine clearance from serum creatinine. Nephron. 1976;16(1):31-41.

11. Levey AS, Coresh J, Greene T, Stevens LA, Zhang YL, Hendriksen S. Using standardized serum creatinine values in the modification of diet in renal disease study equation for estimating glomerular filtration rate. Ann Intern Med. 2006;145(4):247-54.

12. Levey AS, Stevens LA, Schmid CH, Zhang YL, Castro AF, Feldman HI. A new equation to estimate glomerular filtration rate. Ann Intern Med. 2009;150(9):604-12.

13. Goldberg TH, Finkelstein MS. Difficulties in Estimating Glomerular Filtration Rate in the Elderly. Arch Intern Med. 1987;147:1430.

14. Dowling TC, Wang ES, Ferrucci L, Sorkin JD. Glomerular Filtration Rate Equations Overestimate Creatinine Clearance in Older Individuals Enrolled in the Baltimore Longitudinal Study on Aging (BLSA): Impact on Renal Drug Dosing. Pharmacotherapy. 2013;33(9):912-921.

15. Swan SK. The Search Continues - An Ideal Marker of GFR. Clin Chem. 1997;43:913-914.

16. Hoek FJ, Kemperman FAW, Krediet RT. A comparison between cystatin C, plasma creatinine and the Cockcroft and Gault formula for the estimation of glomerular filtration rate. Nephrol Dial Transplant. 2003;18(10):2024-31.

17. Larsson A, Malm J, Grubb A, Hansson LO. Calculation of glomerular filtration rate expressed in $\mathrm{mL} / \mathrm{min}$ from plasma cystatin $\mathrm{C}$ values in $\mathrm{mg} / \mathrm{L}$. Scand $\mathrm{J}$ Clin Lab Invest. 2004;64(1):25-30.

18. Grubb A, Nyman U, Bjo J, Lindstro V, Rippe B, Sterner G. Simple Cystatin C-Based Prediction Equations for Glomerular Filtration Rate Compared with the Modification of Diet in Renal Disease Prediction Equation for Adults and the Schwartz and the Counahan - Barratt Prediction Equations for Children. Clin Chem. 2005;51(8):1420-31.

19. Flodin M, Larsson A, Jonsson AS, Hansson LO, Danielsson LA. Evaluation of Gentian cystatin C reagent on Abbott Ci8200 and calculation of glomerular filtration rate expressed in $\mathrm{mL} / \mathrm{min} / 1.73 \mathrm{~m} 2$ from the cystatin $\mathrm{C}$ values in $\mathrm{mg} / \mathrm{L}$. Scand J Clin Lab Invest. 2007;67(5):560-67.

20. Fiseha T. Clinical Significance of Cystatin C-Based Estimates of Renal Function in Type 2 Diabetic Patients: Review. Ann Clin Lab Res. 2015;3:1-10.

21. Levey AS, Fan L, Eckfeldt JH, Inker LA. Cystatin C for glomerular filtration rate estimation: Coming of age. Clin Chem. 2014;60:916-19.

22. Ma YC, Zuo L, Chen JH, Luo Q, Yu XQ, Li Y, . Modified Glomerular Filtration Rate Estimating Equation for Chinese Patients with Chronic Kidney Disease. J Am Soc Nephrol. 2006;17(10):2937-44.

23. Matsuo S, Imai E, Horio M, Yasuda Y, Tomita K, Nitta K, et al. Revised Equations for Estimated GFR From Serum Creatinine in Japan. Am J Kidney Dis. 2009;53(6):982-92.

24. Fisher RA. On the "probable error' of a coefficient of correlation deduced from a small sample. Metron. 1921;1:205-35.

25. Jaffe MU den N. Über den Niederschlag, welchen Pikrinsäre in normalem Harn erzeugt und über eine neue Reaction des Kreatinins. Hoppe Seylers Z Physiol Chem. 1886;10(5):391-400. 
26. Thakkar H, Newman DJ, Holownia P, Davey CL, Wang CC, Lloyd J, et al. Development and validation of a particle-enhanced turbidimetric inhibition assay for urine albumin on the Dade aca analyzer. Clin Chem. 1991;43(1):109-13.

27. Du Bois $D$, Du Bois EF. A formula to estimate the approximate surface area if height and weight be known. Nutrition. 1989;5:303-11.

28. Ferguson MA, Waikar SS. Established and emerging markers of kidney function. Clin Chem. 2012;58:680-89.

29. Tenstad O, Roald A, Grubb A, Aukland K. Renal handling of radiolabelled human cystatin $C$ in the rat. Scand J Clin Lab Invest. 1996;56:409-14.

30. Jacobsson B, Lignelid $\mathrm{H}$, Bergerheim US. Transthyretin and cystatin $\mathrm{C}$ are catabolized in proximal tubular epithelial cells and the proteins are not useful as markers for renal cell carcinomas. Histopathology. 1995;26:559-64.

31. Levey AS, Inker LA, Coresh J. GFR Estimation: From Physiology to Public Health. Am J Kidney Dis. 2014;63(5):820-34.

32. Levey AS, Inker LA. Assessment of Glomerular Filtration Rate in Health and Disease: A State of the Art Review. Clin Pharmacol Ther. 2017;102(3):405-19.

33. Lee HS, Rhee H, Seong EY, Lee DW, Lee SB, Kwak IS. Comparison of glomerular filtration rates calculated by different serum cystatin C-based equations in patients with chronic kidney disease. Kidney Res Clin Pract. 2014;33(1):45-51.

34. Bland JM, Altman DG. Statistical methods for assessing agreement between two methods of clinical measurement. Lancet. 1986;327(8476):307-10.

35. Xirouchakis E, Marelli L, Cholongitas E, Manousou P, Calvaruso V, Pleguezuelo M, . Comparison of Cystatin C and Creatinine-based Glomerular Filtration Rate Formulas with $51 \mathrm{Cr}$-EDTA. Clin J Am Soc Nephrol. 2011;6(1):84-92.

36. Jalalonmuhali M, Elagel SMA, Tan MP, Lim SK, Ng KP. Estimating Renal Function in the Elderly Malaysian Patients Attending Medical Outpatient Clinic: A Comparison between Creatinine Based and Cystatin-C Based Equations. Int J Nephrol. 2018;2018:1-6.
37. Marwyne MNN, Loo CY, Halim AG, Norella K, Sulaiman T, Zaleha MI. Estimation of glomerular filtration rate using serum cystatin $C$ in overweight and obese subjects. Med J Malaysia. 2011;66(4):313-7.

38. Maiwall R, Kumar A, Bhardwaj A, Kumar G, Bhadoria AS, Sarin SK. Cystatin C predicts Acute Kidney Injury and Mortality in Cirrhotics: A Prospective Cohort Study. Liver Int. 2018;38(4):654-64.

39. DeCarolis DD, Thorson JG, Marraffa RA, Clairmont MA, Kuskowski MA. Comparison of Equations With Estimate Renal Function to Predict Serum Vancomycin Concentration in Patients With Spinal Cord Injury-Does the Use of Cystatin C Improve Accuracy? Ther Drug Monit. 2014;36(5):632-9.

40. Chin PKL, Chew-Harris JSC, Florkowski CM, Begg EJ. The performance of contemporary cystatin C-based GFR equations in predicting gentamicin clearance. Br J Clin Pharmacol. 2015;79(2):268-77.

41. Chen Y, Feng J, Li B, Zhang L, Yang Y. Estimation of safe and effective dose of vancomycin in MRSA-infected patients using serum cystatin C concentrations. Int J Clin Pharmacol Ther. 2013;51(3):161.

42. Naicker J. Glomerular filtration rate (GFR) and estimation of the GFR (eGFR) in adults. Contin Med Educ. 2012;30(7):235-237.

43. Allander SV, Marké LÅ, Wihlen B, Svensson M, Elinder CG, Larsson A. Regional variation in use of exogenous and endogenous glomerular filtration rate (GFR) markers in Sweden. Ups J Med Sci. 2012;117(3):273-8.

44. Lamb EJ, Stevens PE, Deeks JJ. What is the best glomerular filtration marker to identify people with chronic kidney disease most likely to have poor outcomes? BMJ. 2015;350:10-3.

45. Inker LA, Schmid CH, Tighiouart H, Eckfeldt JH, Feldman, HI, Greene T. Estimating Glomerular Filtration Rate from Serum Creatinine and Cystatin C. N Engl J Med. 2012;367:20-9.

\section{PICTORIAL ABSTRACT}

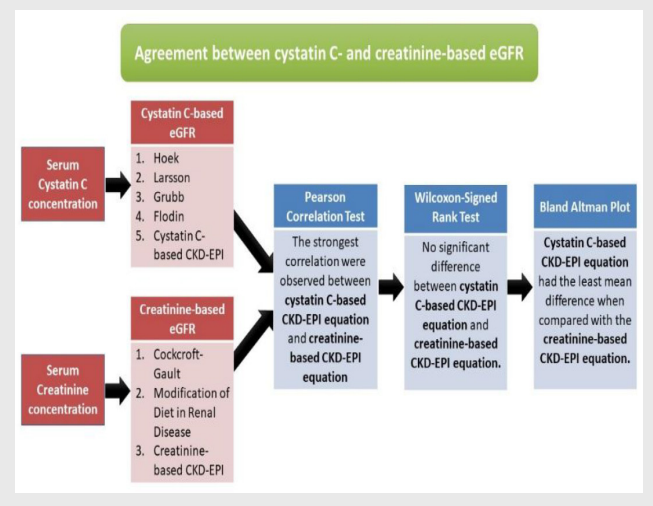

\section{Summary}

- All cystatin C-based eGFR equations shows a statistically significant correlation with creatinine-based eGFR equations amongst Malaysian patients with CKD.

- eGFR values derived from cystatin C-based CKD-EPI equation shows the highest correlation and the least mean difference from baseline with creatinine-based CKD-EPI equation.

- Cystatin C-based eGFR equation will be a good alternative to creatinine-based eGFR equations in drug dose adjustment of renally excreted drugs.

\section{About Authors}

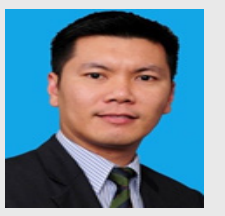

Associate Professor Dr Mohd Makmor-Bakry is the Deputy Dean (Research and Innovation) at the Faculty of Pharmacy, Universiti Kebangsaan Malaysia. He completed his Bachelor of Pharmacy (Hons) at Universiti Kebangsaan Malaysia in 1999 and his Master of Pharmacy (Clinical) at Universiti Sains Malaysia in 2000. He then obtained his Doctor of Philosophy (Medicine \& Therapeutics) from the University of Glasgow, Scotland in 2007 . He is the recipient of the Malaysia National Academic Award (Teaching Category) in 2017 and UKM Excellent Teaching Award (Health Science) in 2013. His specialisation and current research interests include Clinical Pharmacy Practice, Clinical Pharmacokinetics and Pharmacotherapy in Epilepsy and Critical Care. 


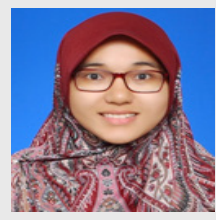

Ms. Nor Asyikin Mohd Tahir is a PhD candidate in the Quality Use of Medicine Research Group at Faculty of Pharmacy, Universiti Kebangsaan Malaysia. She is supervised by Associate Professor Dr Mohd Makmor-Bakry. She obtained her Bachelor of Pharmacy at University of Otago, New Zealand (2015). Her research mainly focused on clinical pharmacy practice and clinical pharmacokinetics.

Cite this article: Mohd Tahir NA, Abdul Gafor AH, Islahudin FH, Mohd Saffian S, Abdul Manan H, Othman H, Makmor-Bakry M. Agreement between Creatinine and Cystatin C-Based Equations in the Estimation of Glomerular Filtration Rate among Malaysian Patients with Renal Impairment. Indian J of Pharmaceutical Education and Research. 2018;52(4 Suppl 2):S257-S267. 